\title{
Risk of Lung Cancer among Japanese Coal Miners on Hazard Risk and Interaction between Smoking and Coal Mining
}

\author{
Motonobu MiYazaki and Hiroshi UnE \\ Department of Hygiene and Preventive Medicine, School of Medicine, Fukuoka University
}

\begin{abstract}
Risk of Lung Cancer among Japanese Coal Miners on Hazard Risk and Interaction between Smoking and Coal Mining: Motonobu MIYAZAKI, et al. Department of Hygiene and Preventive Medicine, School of Medicine, Fukuoka University-This article examines whether an association is found between lung cancer and coal mining and also whether a correlation is found between smoking and coal mining that relates to the risk of lung cancer in Japanese coal miners. A cohort study was performed in former coal mine areas. The survey was carried out between 1987 and 1989, and was extended in a follow-up period to 1995 . 5,818 Japanese males $(1,796$ coal miners and 4,022 non-coal miners) aged from 40 to $69 \mathrm{yr}$ responded to a mail questionnaire that included occupational history and smoking habits. The data were analysed with Cox's proportional hazards model. Significant differences in hazard ratios for lung cancer were recognized in coal miners with $\geq 15 \mathrm{yr}$ of work (Hazard ratio $=2.08,95 \% \mathrm{Cl}: 1.01-4.27$ ) and current smokers with $\geq 20$ cigarettes/day (Hazard ratio $=5.41,95 \% \mathrm{Cl}: 1.26-23.28$ ). As regards the interaction of coal mining and smoking, the hazard ratios were $2.04(95 \% \mathrm{Cl}: 0.13-32.83)$ for coal miners who had never smoked, 4.71 (95\% Cl: 0.62-35.56) for non-coal miners who were ex-smokers or current smokers, and 6.88 (95\% Cl: $0.92-51.65)$ for coal miners who were ex-smokers or current smokers compared with non-coal miners who had never smoked. The interaction of coal mining and smoking for the risk of lung cancer was likely to be additive rather than synergistic.
\end{abstract}

(J Occup Health 2001; 43: 225-230)

Key words: Lung cancer, Smoking, Duration of coal mining, Japanese coal miners

Since the publication of the International Agency for Research on Cancer (IARC) monograph in 1987

Received Dec 26, 2000; Accepted April 20, 2001

Correspondence to: $M$. Miyazaki, Department of Hygiene and Preventive Medicine, School of Medicine, Fukuoka University, 745-I Nanakuma, Jonan-ku, Fukuoka City 814-0180, Japan indicating that silica was a probable human carcinogen "), there has been an extensive debate about the cancer risks among silicosis. In 1997 a follow-up meeting was convened which reevaluated silica as a Group I carcinogen concluding that there was sufficient evidence for carcinogenicity in experimental animals and sufficient evidence for carcinogenicity in humans ${ }^{2}$. Typical silicosis patients are stone workers, mine and quarry workers, foundry workers, construction workers, and glass, clay, and pottery workers ${ }^{3.4)}$. Many epidemiological studies point to an excess of lung cancer in silica exposed workers. The potential mechanisms are still controversial: the contribution of smoking to the onset of lung cancer in silica exposed workers is another important issue ${ }^{5}$. Some investigators suggest that the excess of lung cancer risk in silicotics is due to smoking $g^{6,7)}$. In addition a synergistic effect between smoking and silica/silicosis for the risk of lung cancer is also likely ${ }^{8}$.

Silica and coal mine dust have been known to induce pulmonary dysfunction in exposed coal miners ${ }^{9.10)}$. However, there are some studies in which no increased risk of lung cancer among coal miners is found ${ }^{11-13)}$. Data on an interaction between smoking and coal mining for the risk of lung cancer are lacking in many studies. As smoking is the most important cause of lung cancer, a possible interaction between smoking and coal mining must be taken into account. Japanese coal miners were exposed to relatively high concentrations of silica dust. The proportion of silica dust in coal mine dust within Japan has been estimated to be about $30 \%{ }^{14}$. Tanaka $e t$ al. ${ }^{151}$ noted that Japanese coal miners tend to suffer from silicosis, and it is known that Japanese coal miners were regularly exposed to mixed coal and silica dust. Although the Japanese coal industry has declined since around 1960, there are still many former coal miners who have silicosis ${ }^{16)}$. Thus an epidemiological study on a risk for lung cancer among coal miners remains of importance and of special interest.

The purpose of this study was to investigate the association between lung cancer and coal mining, taking 
account of smoking habit and the duration of work in coal mining, and to evaluate whether an interaction between smoking and coal mining is linked with an increased risk of lung cancer among Japanese coal miners. We analyse and discuss sources of the lung cancer risk in relation to coal mining.

\section{Subjects and Methods}

For this cohort study on the lung cancer risk in coal miners, three towns were selected in a former coal mine district named Chikuhou Coal Mine, the biggest one in Japan. Coal mining had been the most productive before around 1955, but it has gradually declined since the 1960s. All coal mines in these areas had been shut down by 1973 because of the decline of the coal industry. Subjects in this study were all males. The total number of the male population aged from 40 to $69 \mathrm{yr}$ in these towns was 9,943 . These subjects were identified from the municipal population registers. A mail survey was undertaken during 1987 to 1989 with a postal questionnaire, including information on medical conditions, smoking habit, alcohol consumption, and occupational history, particularly a history of coal mining. Data on smoking habits included age started, numbers of cigarettes smoked/d, duration, and age stopped, if pertinent. Coal mining information was obtained through a questionnaire on whether the subjects had worked in coal mining, when the coal mining began, and the numbers of years worked in coal mines.

The follow-up period extended from the time of the mail survey to February 1995. Two hundred and fortyfive emigrants were identified through the municipal population registers. We identified all causes of deaths from death certificates. Causes of death were coded according to the 9 th revision of the International Classification of Diseases (ICD-9). Person-years were calculated from the specific date of the mail survey during 1987-1989 until death, emigration, or the end of the follow-up (February 28th, 1995). The periods observed were 10,262 person-years for coal miners and 23,018 person-years for non-coal miners.

The smoking habit was grouped into four categories: current smokers of 20 cigarettes or more per day ( $\geq 20$ cigarettes/d), current smokers of 1-19 cigarettes per day $(<20$ cigarettes/d), ex-smokers, and nonsmokers.

In order to evaluate the effect of smoking on the association between coal mining and lung cancer, both current smokers and ex-smokers were included in smoking (+). To clarify the interaction of coal mining and smoking, these factors were classified into four categories by whether specific types of experience existed or not; coal mining $(-)$ and smoking $(-)$, coal mining $(+)$ and smoking $(-)$, coal mining $(-)$ and smoking $(+)$, coal mining $(+)$ and smoking $(+)$. Hazard ratios were calculated as the reference based on both coal mining (-) and smoking (-). The presence of interaction between factors was examined.

Cox's proportional hazards model was applied to determine the hazard ratios and $95 \%$ confidence intervals (CI) of coal mining, smoking, and the interaction of coal mining and smoking for the risk of lung cancer. In these analyses, age, smoking habit, and years of experience working in coal mining were included as independent variables. All data were analysed with the Statistical Analysis System (SAS) software package (SAS Institute, Cary, NC, USA). Unless otherwise stated, the term statistically "significant" was used to designate a $p$ value $<0.05$.

\section{Results}

Table 1 shows the age distribution, years of experience worked in coal mining, and numbers of cigarettes smoked by coal miners and non-coal miners at the start of the follow-up period. We classified subjects into two groups according to whether they had worked as coal miners for at least 2 years: a coal miner group and a non-coal miner group. Of the 9,943 males, 5,818 males $(1,796 \mathrm{coal}$ miners and 4,022 non-coal miners) responded to the questionnaire and the response rate was $58.5 \%$. Work experience in coal mining was categorized as follows: non-coal miners, coal miners with less than $15 \mathrm{yr}$ of experience $(<15 \mathrm{yr})$, and coal miners with at least $15 \mathrm{yr}$ of experience $(\geq 15 \mathrm{yr})$. Seventeen hundred and ninetysix coal miners were divided into two groups according to years of experience; 985 coal miners with $<15 \mathrm{yr}$ and 811 coal miners with $\geq 15$ yr.

Table 2 shows the causes of death in coal miners and non-coal miners. During the follow-up period, 197 of the coal miners and 206 of the non-coal miners died. Twenty-three deaths from lung cancer were identified in the coal miners.

Table 3 shows the hazard ratios and $95 \% \mathrm{CI}$ for lung cancer. In these analyses, age, smoking habit, and years of work experience in coal mining were included as independent variables. The hazard ratio for lung cancer was 2.08 (95\% CI: $1.01-4.27$ ) for coal miners with $\geq 15$ $\mathrm{yr}$ and it was statistically significant $(\mathrm{p}<0.05)$. However, a clear association was not observed in the hazard ratio for coal miners with $<15$ yr compared with non-coal miners.

As regards the smoking habit, the hazard ratio for lung cancer for current smokers with $\geq 20$ cigarettes/d was 5.41 (95\% CI: 1.26-23.28) and it was a statistically significant increase $(\mathrm{p}<0.05)$. The hazard ratio of lung cancer for current smokers with $<20$ cigarettes/d is also elevated, but this was considered insignificant.

Table 4 shows the interaction between coal mining and smoking for lung cancer. Out of the total 23 cases of lung cancer in coal miners, 22 were classified as with smoking $(+)$ and one case was included in the smoking 
Table 1. Age distribution, years of experience working at coal mining, and numbers of cigarette smoked by coal miners and non-coal miners

\begin{tabular}{lrr} 
& $\begin{array}{c}\text { Number of } \\
\text { coal miners }\end{array}$ & $\begin{array}{c}\text { Number of } \\
\text { non-coal miners }\end{array}$ \\
\hline Age & & \\
$\quad 40-49$ & $122(6.8 \%)$ & $1,652(41.1 \%)$ \\
$50-59$ & $595(33.1 \%)$ & $1,344(33.4 \%)$ \\
$60-69$ & $1,079(60.1 \%)$ & $1,026(25.5 \%)$ \\
Experience worked in coal mining & & \\
$<15$ yr & $985(54.8 \%)$ & \\
$\geq 15$ yr & $811(45.2 \%)$ & \\
Smoking habit & $262(14.6 \%)$ & $987(24.5 \%)$ \\
Nonsmokers & $482(26.8 \%)$ & $917(22.8 \%)$ \\
Ex-smokers & & \\
Current smokers & & \\
1-19 cigarettes/d & $430(23.9 \%)$ & $603(15.0 \%)$ \\
$20-$ cigarettes/d & $622(34.6 \%)$ & $1,515(37.7 \%)$ \\
\hline
\end{tabular}

Notes: Coal miners were defined as coal miners with at least 2 years' experience. Non-coal miners were defined as non-coal miners or coal miners with less than 2 years' experience. The mean years of experience for 1,796 coal miners is $14.3 \pm 9.8$ (mean \pm SD). The mean age of 985 coal miners with $<15 \mathrm{yr}$ experience is $58.5 \pm 6.7$. The mean age of 811 coal miners with $\geq 15 \mathrm{yr}$ worked is $63.0 \pm 4.6$. The mean age of 4,022 non-coal miners is $53.2 \pm 8.5$.

Table 2. Causes of death among coal miners and non-coal miners

\begin{tabular}{lccr}
\hline Cause of death & $\begin{array}{c}\text { Number of } \\
\text { coal miners }\end{array}$ & $\begin{array}{c}\text { Number of } \\
\text { non-coal miners }\end{array}$ & Total \\
\hline All causes & 197 & 206 & 403 \\
All cancers & 105 & 95 & 200 \\
$\quad$ Lung cancer & 23 & 17 & 40 \\
Heart diseases & 25 & 22 & 47 \\
Stroke & 9 & 25 & 34 \\
Pneumoconiosis & 11 & 0 & 11 \\
\hline
\end{tabular}

Table 3. Hazard ratios for experience in coal mining and smoking habit for lung cancer

\begin{tabular}{lcc}
\hline Factors & Hazard ratios & $95 \%$ Confidence intervals \\
\cline { 3 - 3 } Age (10-yr interval) & 3.43 & $1.87-6.32 * * *$ \\
Experience in coal mining & & \\
$\quad$ Non-coal miners & 1.00 & \\
$<15 \mathrm{yr}$ & 1.00 & $0.41-2.43$ \\
$\geq 15 \mathrm{yr}$ & 2.08 & $1.01-4.27 *$ \\
Smoking habit & & \\
Nonsmokers & 1.00 & $0.79-15.85$ \\
Ex-smokers & 3.52 & \\
Current smokers & & $0.57-13.30$ \\
$\quad 1-19$ cigarettes/d & 2.47 & $1.26-23.28 *$ \\
$20-$ cigarettes/d & 5.41 & \\
\hline
\end{tabular}

Notes: Adjusted for the other factors in this table. $p<0.05^{*}, \mathrm{p}<0.001^{* * * *}$. 
Table 4. Interaction of coal mining and smoking for lung cancer

\begin{tabular}{lcccc}
\hline \multirow{2}{*}{ Factors } & $\begin{array}{c}\text { Number of } \\
\text { subjects }\end{array}$ & $\begin{array}{c}\text { Number of } \\
\text { cases }\end{array}$ & $\begin{array}{c}\text { Hazard } \\
\text { ratios }\end{array}$ & $\begin{array}{c}95 \% \text { Confidence } \\
\text { intervals }\end{array}$ \\
\cline { 3 - 6 } Age (10-yr interval) & & & 3.38 & $1.86-6.14 * * *$ \\
Coal mining (-) and Smoking (-) & 986 & 1 & 1.00 & \\
Coal mining (+) and Smoking (-) & 263 & 1 & 2.04 & $0.13-32.83$ \\
Coal mining (-) and Smoking (+) & 3,036 & 16 & 4.71 & $0.62-35.56$ \\
Coal mining (+) and Smoking (+) & 1,533 & 22 & 6.88 & $0.92-51.65$ \\
\hline
\end{tabular}

Notes: Adjusted for the other factors in this table. Number of cases means the number of deaths from lung cancer. $P<0.001^{* * *}$.

group (-). Of 17 cases of lung cancer in non-coal miners, 16 had smoked, but 1 had not. The most striking finding was the high risk in coal miners who smoked (+), although it was not significant, whereas the hazard ratios were 2.04 for coal miners who were non-smokers and 4.71 for noncoal miners who were ex-smokers or current smokers. Therefore, this study found that the interaction between coal mining and smoking for the risk of lung cancer was likely to be an additive effect rather than a synergistic effect.

\section{Discussion}

The main purpose of this study is to obtain a better understanding of human risk of lung cancer associated with coal mining, and to investigate the interaction between coal mining and smoking. To avoid the effect of geographical variations in the risk of lung cancer, we compared the risk for coal miners and non-coal miners living in the same area and sharing similar environment factors. The prevalence of cigarette smoking was almost the same in the two groups. Of total deaths lung cancer accounted for $11.7 \%$ in coal miners and $8.3 \%$ in noncoal miners. Compared with the Japanese male mortality as a standard, the standardized mortality ratios (SMRs) for lung cancer were 152 in coal miners and 92 in noncoal miners ${ }^{16 !}$, but these SMRs were not found to constitute a significant difference, although a significant SMR of 138 was found for lung cancer in corresponding areas in our separate study ${ }^{17}$.

Smoking is the major cause of lung cancer. The interaction of lung cancer with exposure to a working environment and the smoking habit is important ${ }^{4}$. 7 . Information on smoking was obtained by a questionnaire. It is possible that the status of males who have been smokers at the time of the mail survey has been correctly ascertained, but there may be some misclassification of males who reported whether they have stopped or never smoked in addition to reporting the numbers of cigarettes/d for current smokers. Nevertheless, some misclassification of the smoking habit is as likely to be present in control subjects as in case subjects ${ }^{(8)}$. That is, it is unlikely that a differential misclassification had a significant impact on the study results. Our results on hazard ratios for current smokers both with $<20$ cigarettes/d and with $\geq 20$ cigarettes/d were almost the same as previous studies about Japanese current smokers (hazard ratio $=1.28-3.18$ and $2.38-8.15$, respectively) ${ }^{\mid 9.20)}$. We therefore suggested that reported numbers of cigarettes smoked/d were not likely to be inaccurate in this study.

The risk increased with the numbers of years worked ${ }^{21}$. Lung cancer was significantly associated with coal mining for $\geq 15 \mathrm{yr}$ in our study. An increased risk was not, however, detected for coal mining for $<15$ yr. Japanese death rates in males from lung cancer clearly increase after the age of $60^{221}$. The average age of coal miners with $<15 \mathrm{yr}$ worked was under the age of 60 . The risk increased with the increase in the duration of work and latency since time of first employment ${ }^{21}$. When they reach 60 or over in the future, the risk of lung cancer among coal miners with $<15$ yr may increase. Therefore, the observation period in our study needs to be extended in the future.

In 1997 an IARC follow-up meeting was convened which reevaluated silica as a Group I carcinogen and concluded that there was sufficient evidence of carcinogenicity in laboratory animals as well as for carcinogenicity in humans ${ }^{2)}$. Most coal miners were exposed to mixed coal and silica dust ${ }^{12}$. Because we undertook a mail survey, our study did not obtain data on dust measurements. However, a few reports showed as follows; coal mines within Japan were thin coal strata ${ }^{161}$ and the proportion of silica dust content in coal mine dust within Japan was estimated to be about $30 \%{ }^{14}$. Surface mining operations generally had high levels of exposure to respirable silica dust ${ }^{21}$. Therefore, it was suggested that Japanese coal miners were exposed to relatively high concentrations of silica dust. It has been found that Japanese coal miners suffer from silicosis ${ }^{15.23}$. However, several reports demonstrate that no risk of lung cancer is found among coal miners in the United Kingdom ${ }^{11}$ ) and the United States ${ }^{131}$. One possible explanation is that the proportion of silica dust in Japanese 
coal mines is different from that in British, United States and German coal mines ${ }^{21}$, and silica dust in coal mines within these countries contains a low level of free silica ${ }^{2.24}$. Several epidemiological investigations indicate a significantly increased risk of lung cancer among silicotics ${ }^{3-7.23 .25 .26 !}$. The risk of lung cancer death is related to the number of years since first silica exposure and the number of years worked ${ }^{6)}$. These facts suggest that the hazard ratio of lung cancer in Japanese coal miners may be related to the high content of silica in the composition of coal dust and the length of coal mining work experience.

Positive reports ${ }^{6,8,10)}$ and negative reports ${ }^{12,24,27)}$ are published about a synergistic relationship between free silica and smoking. Several reports show that silica dust exposure is associated with increased risk of Jung cancer ${ }^{6,28,291}$. Because coal mine dust within Japan contains a high level of free silica ${ }^{14)}$, there also emerges the question of whether both coal mining and smoking act synergistically to increase the risk of lung cancer. The interaction between coal mining and smoking for the risk of lung cancer was examined. The hazard ratio for lung cancer among non-cigarette smoking coal miners was 2.04 times higher than that among non-cigarette smoking non-coal miners. The hazard ratio for cigarette smokers among non-coal miners was 4.71 times higher in the induction of lung cancer, than for non-cigarette smoking non-coal miners. In addition, the combination of coal mining with cigarette smoking was 6.88 times higher in lung cancer induction than in non-cigarette smoking noncoal miners.

In some previous reports ${ }^{7.8 .101}$ a synergistic effect of smoking and silica/silicosis on the risk of lung cancer was found to be likely. Cigarette smoking was found to be a strong predictor of the lung cancer risk ${ }^{181}$. Nevertheless, although cigarette smoking has the stronger effect, several reports show that a nonsynergistic effect is apparent between cigarette smoking and silica dust exposure for the risk of lung cancer ${ }^{18,24,27}$. A synergistic result of the interaction was not clearly seen in our study. However, our results suggested that the interaction of coal mining and cigarette smoking for the risk of lung cancer was likely to be additive rather than synergistic.

An important factor in disease development may be the retention time of dust in the lung, so that earlier exposure might have a greater influence on disease development ${ }^{530)}$. There is an increase in the risk of lung cancer with increasing time (not necessarily continuous) since first employment $t^{6.31)}$. The highest risk of lung cancer death occurred after more than $30 \mathrm{yr}$ since first exposure and in those who had had more than 30 years' experience on the job ${ }^{71}$. These facts suggest the importance of evaluating the duration of work experience, latency from first employment, and time since cessation of work. In addition, a basic debate continues as to whether mechanisms about smoking affection are initiators, promoters, or both ${ }^{321}$, and it is not resolved whether a synergistic effect between coal mining and cigarette smoking for the risk of lung cancer exists or not. It seems that a further follow-up of the data would improve the certainty of results. Therefore, a study should be focused in the next extension of follow-up time for coal miners to distinguish the interaction of coal mining and cigarette smoking, to evaluate the risk for lung cancer in coal miners with $<15 \mathrm{yr}$ of coal mining experience at the age of 60 or over, and to compare it with the risk for lung cancer among ex-smokers and current smokers with I-19 cigarettes/d.

Although we also mentioned that the response rate of the survey was relatively low at $58.5 \%$ in our previous study ${ }^{33}$, we could not clarify whether it caused a bias in the results. However, we arrived at the following conclusions in our study: The interaction of coal mining and cigarette smoking was not likely to be synergistic but seemed to be additive for the risk of lung cancer Important trends for a risk of lung cancer were evidently found for current smokers of $\geq 20$ cigarettes/d and for coal miners who had worked $\geq 15$ yr. Moreover, survivors who were coal miners, regardless of smoking, should be examined through clinical screening for early detection of lung cancer under the most cost effective program, because the risk of lung cancer remains. A study is needed to clarify the role of these factors in the evaluation of the risk of lung cancer and coal miners in the future.

\section{References}

1) International Agency for Research on Cancer. Working Group on the evaluation of carcinogenic risk of chemicals to humans. Silica and some silicates. In: IARC monographs on the evaluation of the carcinogenic risk of chemicals to humans. Vol. 42 . Lyon: IARC, 1987: 39-143.

2) International Agency for Research on Cancer. Silica. some silicates, coal dust and para-aramid fibriles. In: IARC monographs on the evaluation of the carcinogenic risk to humans. Vol. 68. Lyon: IARC, 1997: 41-371.

3) Brown LM, Gridley G, Olsen JH, Mellemkjaer L, Linet MS, Fraumeri JF. Cancer risk and mortality patterns among silicotic men in Sweden and Denmark. J Occup Environ Med 1997; 39: 633-638.

4) Oksa P, Pukkala E, Karjalainen A, Ojajarvi A, Huuskonen MS. Cancer incidence and mortality among Finnish asbestosis sprayers and in asbestosis and silicosis patients. Am J Ind Med 1997; 31: 693-698.

5) Meijers JMM, Swaen GMH, Slangen JJM. Mortality and lung cancer in ceramic workers in the Netherlands: Preliminary results. Am J Ind Med 1996; 30: 26-30.

6) Zambon P, Simonato L, Mastrangelo $G$, Winkelmann R, Saia B, Crepet M. Mortality of workers compensated for silicosis during the period 1959-1963 in the Veneto region of Italy. Scand J Work Environ Health 1987 ; 
13: $118-123$.

7) $\mathrm{Ng} \mathrm{TP}$, Chan SL, Lee J. Mortality of a cohort of men in a silicosis resister: Further evidence of an association with lung cancer. Am J Ind Med 1990; 17: 163-171.

8) Hnizdo E, Sluie-Cremer GK. Silica exposure, Silicosis, and lung cancer: a mortality study of south African gold miners. Br I Ind Med 1991; 48: 53-60.

9) Lewis S, Bennett J, Richards K, Britton J. A cross sectional study of the independent effect of occupation on lung function in British coal miners. Occup Environ Med 1996; 53: 125-128.

10) Wang $X$, Yano E, Nonaka K, Wang M, Wang Z. Respiratory impairments due to dust exposure: A comparative study among workers exposed to silica, asbestos, and coalmine dust. Am J Ind Med 1997; 31 : 495-502.

11) Miller BG, Jacobsen M. Dust exposure, pneumoconiosis, and mortality of coal miners. Br J Ind Med 1985; 42: 723-733.

12) Leigh J, Driscoll TR, Cole BD, Beck RW, Hull BP, Yang J. Quantitative relation between emphysema and lung mineral content in coalworkers. Occup Environ Med 1994; 51: 400-407.

13) Kuempel ED, Stayner LT, Attfield MD, Buncher $\mathrm{CH}$. Exposure-response analysis of mortality among coal miners in the United States. Am J Ind Med 1995; 28 : 167-184.

14) Ishinishi S. Silicosis. Fukuoka Acta Med 1956; 47 : 926-930 (in Japanese).

15) Tanaka S, Naruo Y, Toyofuku T. Silicosis and Silicotuberculosis in a coalmine. Jpn J Ind Med 1960; 2: 622-628.

16) Une H, Esaki H, Osajima K, Ikui H, Kodama K, Hatada $\mathrm{K}$. A prospective study on mortality among Japanese coal miners. Ind Health 1995; 33: 67-76.

17) Tateishi N, Osajima K, Watanabe D, Une H, Esaki $H$, Shigematsu T. Studies on the geographical difference in mortality for selected causes of death in Fukuoka Prefecture, 1983-1987. Med Bull Fukuoka Univ 1995; 22: 73-90 (in Japanese).

18) Andjelkovich DA, Shy CM, Brown MH, Janszen DB, Levine RJ, Richardson RB. Mortality of iron foundry workers III: Lung cancer case-control study. J Occup Med 1994; 36: 1301-1309.

19) Kono S, Ikeda M, Tokudome S, Nishizumi M, Kuratsune M. Cigarette smoking, alcohol and cancer mortality: a cohort study of Male Japanese physicians.
Jpn J Cancer Res 1987; 78: 1323-1328.

20) Sobue T, Suzuki T, Fujimoto I, Doi O, Tateishi R, Sato T. Prognostic factors for surgically treated lung adenocarcinoma patients, with special reference to smoking habit. Jpn J Cancer Res 1991; 82: 33-39.

21) Rosenman KD, Stanbury M. Risk of lung cancer among former chromium smelter workers. Am J Ind Med 1996; 29: 491-500.

22) Ministry of Health and Welfare. Vital statistics of Japan 1994; 1: 120-289 (in Japanese).

23) Amandus H, Shy C, Wing S, Blair A, Heineman E. Silicosis and lung cancer in North California dusty trade workers. Am J Ind Med 1991; 20: 57-70.

24) Carta P, Cocco PL, Casula D. Mortality from lung cancer among Sardinian patients with silicosis. Br J Ind Med 1991; 48: 122-129.

25) Wang QS, Boffetta P, Parkin M, Kogevinas M. Occupational risk factors for lung cancer in Tianjin, China. Am J Ind Med 1995; 28: 353-362.

26) Tsuda T, Babazono A, Yamamoto E, Mino Y, Matsuoka H. A meta-analysis on the relationship between pneumoconiosis and lung cancer. J Occup Health 1997 39: 285-294.

27) Hua F, Xueqi G, Xipeng J, Shunzhang Y, Kaiquo W, Guidotti TL. Lung cancer among Tin miners in southeast China: Silica exposure, silicosis, and cigarette smoking. Am J Ind Med 1994; 26: 373-381.

28) Simonato L, Fletcher AC, Saracci R, Thomas TL. Occupational exposure to silica and cancer risk. Lyon: IARC, IARC scientific publication, no. 97, 1990.

29) Stefani ED, Kogevinas M, Boffeta P, Ronco A, Mendilaharsu $M$. Occupation and the risk of lung cancer in Uruguay. Scand J Work Environ Health 1996; 22: 346-352.

30) Huerley FF, Alexander WP, Hazeldine DJ, Jacobsen M, MaClaren WM. Exposure to respirable coal mine dust and incidence of progressive massive fibrosis. $\mathrm{Br}$ J Ind Med 1987; 44: 661-672.

31) Rafnsson V, Gunnarsdottri H, Kiilunen M. Risk of lung cancer among masons in Ireland. Occup Environ Med 1997; 54: 184-188.

32) Steenland K. Age specific interactions between smoking and radon among United States uranium miners. Occup Environ Med 1994; 51: 192-194.

33) Une H, Miyazaki M, Momose Y. Comparison of mortality between respondents and non-respondents in a mail survey. J Epidemiol 2000; 10: 136-139. 